\title{
Perspectives in Primary Care: Disseminating Scientific Findings in an Era of Fake News and Science Denial
}

\author{
Arch G. Mainous III, $P b D^{1,2}$ \\ 'Department of Health Services Research, Management, and Policy, University of Florida, Gainesville, Florida \\ ${ }^{2}$ Department of Community Health and Family Medicine, University of Florida, Gainesville, Florida \\ Ann Fam Med 2018;16:490-491. https://doi.org/10.1370/afm.2311.
}

S cience and research findings have become a battleground on which to influence the opinions and beliefs of the general public. We are in an era where authority figures will manipulate and discount information being released to the public that doesn't fit their worldview or support their plan of action. We hear constant claims of "fake news" for positions with evidence while simultaneously hearing support for policy positions that clearly have no scientific evidence. The Environmental Protection Agency (EPA) removed scientists from panel discussions on climate science so that the scientists were unable to publicly present their findings. ${ }^{1}$ Further, although evidence indicates that childhood immunizations are not associated with autism, the persistent belief in the harmfulness of childhood immunizations and the corresponding information disseminated by anti-vaccine groups has led to low vaccine rates and measles outbreaks in places like the Somali community in Minnesota. ${ }^{2-4}$

In a world of misinformation, public understanding of medical research and advances has never been more important. Unfortunately, the general public is targeted with messages by groups who may not be providing the public with the most accurate information. Furthermore, scientists who only disseminate their findings to each other and write only for other scientists miss a key constituency-the general public. This Perspective discusses critically important

Conflicts of interest: author reports none.

\section{CORRESPONDING AUTHOR}

Arch G. Mainous III, PhD

Department of Health Services Research, Management, and Policy University of Florida

Health Sciences Center, PO Box 100195

Gainesville, FL 32610 USA

arch.mainous@phhp.ufl.edu strategies for disseminating research findings to the general public.

\section{HOW IT'S MADE}

1. As you finish writing up your research paper it is important that you think of 2 audiences for your study-the scientific and the general public. Many researchers either don't know how or aren't interested in appealing to the general public, but ignoring them as an audience is a mistake for primary care research and science in general. Research funding is affected by motivated individuals in the general public who influence voters and legislators. Health policy is influenced by motivated individuals who reduce complex ideas to sound bites that support their position. Those sound bites may be based on inaccurate information but, as the people disseminating those messages know, they are very effective in achieving their policy goals. Researchers need to disseminate accurate information that can be consumed by the general population if we want the public to have health literacy.

The goal of disseminating the research to the general public isn't specifically to counter the incorrect message of others, although that may be a secondary benefit. It is important to note that some opinion leaders have labeled particular policy positions "junk science" and then when asked to present the evidence for that position responded, "I am not a scientist." You are the scientific expert and that credibility is very persuasive. The goal is to get the right information out.

Think of a conversation you might have with a parent, sibling, or someone outside of the medical field. If you were going to tell your mother what you do for a living and you were going to use your most recent study, how would you describe the reason why you did the study, what you found, and what it means for her? Let's say that you did a study on the overuse of antibiotics for respiratory infections in primary care. The 
policy position following from the results of this study may be to restrict antibiotic prescribing. You would need to explain to her why and what that means for her health and ability to get treatment even if she has historically received antibiotics for respiratory infections. You may have some convincing to do to change her health belief. Even if it is relevant, you wouldn't go on a long discussion on plasmids and transposons and exchange of antibiotic-resistant DNA (unless you want her to continue to wonder what you do for a living). You want a short, simple message that is easily understandable, a "pitch." It might be something like:

"Antibiotics are useful medicines but a lot of the germs that cause colds and bad coughs are not affected by antibiotics so they really don't help you get better. Using antibiotics wrong can make it so that antibiotics don't work when you are really sick and need an effective treatment. Our study found that more than half of the people who went to doctor with a cold got antibiotics. To make sure that antibiotics continue to work when we need them it is important that doctors give out antibiotics only for germs where we know the antibiotics work."

2. Understand that you are not completely alone in creating your pitch and disseminating your message. Many media outlets are looking for new health-related studies because of great general public interest. Media outlets also want the message to come from the expert who did the study. Craft a message with the journal or university media liaisons that can be easily understood by the general public. This will be sent out in a press release to media outlets. It must be short and have an immediate understanding by the general public and, importantly, have personal relevance to them. You may need to help the media officer understand why you did the study, what you found, and what it means. Remember, these individuals are not medical researchers and thus working with them on your pitch is a good way to understand what parts of your message are not clear and how it will resonate with your target audience.

Many of the messages for nonevidence-based positions sway the public by using very simple messaging like, "if your child gets immunized she will get autism." They may add some additional scientific wording to increase credibility of the message. The scientific terms may be intentionally misleading because they have realized that the science itself isn't the key, but rather the simplicity of the message and the relevance to the lay public. In other words, an effective message must be something like, "our study found that eating fried butter at the county fair increases your risk of a heart attack and dying." That message is short and encapsulates a specific message that relates to the patient's behavior and the consequences of that behavior. It is important that medical jargon that may have been required by peer reviewers is not included in this messaging. You always have the science as backup.

3. Make sure that you are available to speak to the media once the press release has been distributed. Remember that they are trying to help you disseminate your findings and so you must be committed to responding to them in a timely manner. Although many media outlets look for the loudest and most outrageous voice and your message will be competing with them, you have a different role. You have scientific credibility as the person who did the study. Stay on message and keep it simple and easy to understand.

\section{CONCLUSION}

Getting the message out to the public in a simple and understandable way through dissemination by the experts is the best way to rise above the din of fake news and science denial and quell the competing voices that will intentionally present nonevidencebased information to the public or label findings that have implications that they don't like as "fake news" or "junk science."

To read or post commentaries in response to this article, see it online at http://www.AnnFamMed.org/content/16/6/490.

Key words: research; communication; public relations

Submitted August 3, 2018; accepted August 10, 2018.

\section{References}

1. King L. Furor erupts over EPA decision to pull climate scientists from panel discussion. USA Today. October 23, 2017. https://www. usatoday.com/story/news/politics/2017/10/23/furor-erupts-overepa-decision-pull-climate-scientists-panel-discussion/789962001/. Accessed Jul 24, 2018.

2. Taylor LE, Swerdfeger AL, Eslick GD. Vaccines are not associated with autism: an evidence-based meta-analysis of case-control and cohort studies. Vaccine. 2014;32(29):3623-3629.

3. Uno Y, Uchiyama T, Kurosawa M, Aleksic B, Ozaki N. Early exposure to the combined measles-mumps-rubella vaccine and thimerosal-containing vaccines and risk of autism spectrum disorder. Vaccine. 2015;33(21):2511-2516.

4. Sohn E. Understanding the history behind communities' vaccine fears. Shots: Health News From NPR website. https://www.npr.org/ sections/health-shots/2017/05/03/526595475/understanding-thehistory-behind-communities-vaccine-fears. Published May 3, 2017. Accessed Jul 24, 2018. 